\title{
Technical Note: Analytical sensitivity analysis of a two parameter recursive digital baseflow separation filter
}

\author{
K. Eckhardt \\ University of Applied Sciences Weihenstephan-Triesdorf, Weidenbach, Germany \\ Correspondence to: K. Eckhardt (klaus.eckhardt@hswt.de)
}

Received: 19 September 2011 - Published in Hydrol. Earth Syst. Sci. Discuss.: 25 October 2011

Revised: 25 January 2012 - Accepted: 30 January 2012 - Published: 13 February 2012

\begin{abstract}
A sensitivity analysis for a well-established baseflow separation technique, a two parameter recursive digital filter, is presented. The sensitivity of the calculated baseflow index to errors or uncertainties of the two filter parameters and of the initial baseflow value is analytically ascertained. It is found that the influence of the initial baseflow value is negligible for long time series. The propagation of errors or uncertainties of the two filter parameters into the baseflow index is expressed by a dimensionless sensitivity index, the ratio between the relative error of the baseflow index and the relative error of the respective parameter. Representative index values are derived by application of the resulting equations to 65 North American catchments. In the mean the parameter $a$, the recession constant, has a stronger influence on the calculated baseflow index than the second filter parameter $\mathrm{BFI}_{\max }$. This is favourable in that $a$ can be determined by a recession analysis and therefore should be less uncertain. Whether this finding also applies for a specific catchment can easily be checked by means of the derived equations.
\end{abstract}

\section{Introduction}

\subsection{The two parameter recursive digital filter}

The aim of baseflow separation is to distinguish two streamflow components: baseflow (groundwater discharging into the stream) and quick flow (surface runoff and interflow). In the past, many separation methods have been proposed, amongst them the two parameter recursive digital filter of Eckhardt (2005), which has since been applied in numerous studies, sometimes under the name of "Eckhardt filter". The equation of this low-pass filter is

$b_{k}=\frac{\left(1-\mathrm{BFI}_{\max }\right) a b_{k-1}+(1-a) \mathrm{BFI}_{\max } y_{k}}{1-a \mathrm{BFI}_{\max }}$ subject to $b_{k} \leq y_{k}$, where $b$ is the baseflow, $y$ is the streamflow, and $k$ is the time step number. The filter has two parameters: the recession constant $a$ and the maximum value $\mathrm{BFI}_{\max }$ of the baseflow index (the long-term ratio of baseflow to total streamflow) that can be modelled by the algorithm.

A key question is how errors and uncertainties in these two parameters affect the results of the separation. A first attempt to answer this question was the empirical sensitivity analysis by Eckhardt (2005). An empirical sensitivity analysis consists of three steps, which are repeated several times:

1. Input of a model (consisting in general of one or more equations) is varied.

2. The model is run.

3. The model output is analysed.

One can also speak of an experimental sensitivity analysis. However, an empirical sensitivity analysis is only a makeshift if an analytical sensitivity analysis, that is an analytical calculation of the error propagation through the model, is not feasible. In the case of Eq. (1), such a calculation of the error propagation is possible and will be presented in Sect. 2.

\subsection{Comparison with other filters}

Equation (1) represents a whole class of filter algorithms which are based on the widely accepted linear storage model (Eckhardt, 2005). Examples are the algorithms of Chapman and Maxwell (1996) and Boughton (1993). The filter of Chapman and Maxwell (1996)

$b_{k}=\frac{a}{2-a} b_{k-1}+\frac{1-a}{2-a} y_{k}$ 
is derived from Eq. (1) for $\mathrm{BFI}_{\max }=0.5$. The filter of Boughton (1993)

$b_{k}=\frac{a}{1+C} b_{k-1}+\frac{C}{1-C} y_{k}$

is equivalent to Eq. (1) with

$C=\frac{(1-a) \mathrm{BFI}_{\max }}{1-\mathrm{BFI}_{\max }}$.

Filter algorithms which rely more on physics have been presented by Furey and Gupta (2001) and Huyck et al. (2005). In the algorithm of Furey and Gupta (2001) $b_{k}$ is a function of $b_{k-d-1}$ and $y_{k-d-1}$. Four parameters have to be specified: the time delay $d$ between precipitation and groundwater recharge, the ratio $c_{1}$ of overland flow to precipitation, the ratio $c_{3}$ of groundwater recharge to precipitation, and the recession constant $a$. Required are time series of streamflow and precipitation. In the algorithm of Huyck et al. (2005) $b_{k}$ is a function of $b_{k-1}, b_{k-d}, b_{k-d-1}, y_{k-d}$, and $y_{k-d-1}$. Twelve parameters have to be specified: $d, c_{1}, c_{3}$, and nine other parameters describing hydraulic characteristics and the shape of the aquifer. Required are not only time series of streamflow and precipitation, but also a digital elevation model and information on the drainable porosity of the soil.

Equation (1) has only two parameters and requires only streamflow data.

Equation (1) and the algorithms of Furey and Gupta (2001) and Huyck et al. (2005) exemplify a fundamental problem in hydrology: The sounder the physical basis is, the more complex is the model and the greater is the number of its parameters. Analytical expressions may exist for some or all of the parameters, yet the problem of parameter uncertainty persists. Both Furey and Gupta (2001) and Huyck et al. (2005) empirically analyse the impact of parameter uncertainty on the results of their algorithm. The increasing physical reliability does not diminish the need for a sensitivity analysis, but enhances it.

\section{Analytical sensitivity analysis}

\subsection{Parameters a and $\mathrm{BFI}_{\max }$}

The analytical sensitivity analysis of the filter Eq. (1) requires the calculation of the partial derivatives of $b_{k}$ with respect to $a$ and $\mathrm{BFI}_{\max }$ :

$$
\begin{gathered}
\frac{\partial b_{k}}{\partial a}=\frac{\left(1-\mathrm{BFI}_{\max }\right)\left(b_{k-1}-\mathrm{BFI}_{\max } y_{k}\right)}{\left(1-a \mathrm{BFI}_{\max }\right)^{2}} \\
\frac{\partial b_{k}}{\partial \mathrm{BFI}_{\max }}=\frac{(a-1)\left(a b_{k-1}-y_{k}\right)}{\left(1-a \mathrm{BFI}_{\max }\right)^{2}}
\end{gathered}
$$

(see Appendix A).
In the following, the considered model output is the baseflow index

$$
\mathrm{BFI}=\frac{\sum_{k=1}^{n} b_{k}}{\sum_{k=1}^{n} y_{k}}=\frac{b}{y}
$$

where $b$ denotes the sum of baseflow and $y$ the sum of streamflow over the whole period of the available streamflow measurements.

The error propagation into the model output BFI is described by the partial derivatives of BFI with respect to $a$ and $\mathrm{BFI}_{\max }$ :

$$
\begin{gathered}
\frac{\partial \mathrm{BFI}}{\partial a}=\frac{1}{y} \frac{1-\mathrm{BFI}_{\max }}{\left(1-a \mathrm{BFI}_{\max }\right)^{2}}\left(b+b_{0}-b_{n}-\mathrm{BFI}_{\max } y\right) \\
\frac{\partial \mathrm{BFI}}{\partial \mathrm{BFI}_{\max }}=\frac{1}{y} \frac{a-1}{\left(1-a \mathrm{BFI}_{\max }\right)^{2}}\left[a\left(b+b_{0}-b_{n}\right)-y\right]
\end{gathered}
$$

(see Appendix A).

In order to get representative BFI values, the filtered hydrographs should be long. In this case the term $b_{0}-b_{n}$ in the Eqs (8) and (9) can be neglected:

$$
\begin{gathered}
\frac{\partial \mathrm{BFI}}{\partial a}=\frac{1}{y} \frac{1-\mathrm{BFI}_{\max }}{\left(1-a \mathrm{BFI}_{\max }\right)^{2}}\left(b-\mathrm{BFI}_{\max } y\right) \\
\frac{\partial \mathrm{BFI}}{\partial \mathrm{BFI}_{\max }}=\frac{1}{y} \frac{a-1}{\left(1-a \mathrm{BFI}_{\max }\right)^{2}}(a b-y) .
\end{gathered}
$$

Now, the question of how an error $\Delta a$ in the filter parameter $a$ propagates into the calculated baseflow index BFI can be answered. Small errors in $a$ cause an error in BFI of

$$
\begin{aligned}
\Delta_{a} \mathrm{BFI} & =\frac{\partial \mathrm{BFI}}{\partial a} \Delta a \\
& =\frac{1}{y} \frac{1-\mathrm{BFI}_{\max }}{\left(1-a \mathrm{BFI}_{\max }\right)^{2}}\left(b-\mathrm{BFI}_{\max } y\right) \Delta a .
\end{aligned}
$$

Correspondingly, small errors $\Delta \mathrm{BFI}_{\max }$ in the filter parameter $\mathrm{BFI}_{\max }$ cause an error in BFI of

$$
\begin{aligned}
\Delta_{\mathrm{BFI}_{\max }} \mathrm{BFI} & =\frac{\partial \mathrm{BFI}}{\partial \mathrm{BFI}_{\max }} \Delta \mathrm{BFI}_{\max } \\
= & \frac{1}{y} \frac{a-1}{\left(1-a \mathrm{BFI}_{\max }\right)^{2}}(a b-y) \Delta \mathrm{BFI}_{\max } .
\end{aligned}
$$

As a measure for the sensitivity of the baseflow index BFI with respect to the parameters $a$ and $\mathrm{BFI}_{\max }$, a dimensionless sensitivity index $S$ is calculated as the ratio between the relative error of BFI and the relative error of the respective parameter. The sensitivity index for the parameter $a$ is 


$$
\begin{aligned}
S(\mathrm{BFI} \mid a) & =\frac{\Delta_{a} \mathrm{BFI}}{\mathrm{BFI}} / \frac{\Delta a}{a} \\
& =\frac{\left(1-\mathrm{BFI}_{\max }\right)\left(\mathrm{BFI}-\mathrm{BFI}_{\max }\right)}{\left(1-a \mathrm{BFI}_{\max }\right)^{2}} \frac{a}{\mathrm{BFI}}
\end{aligned}
$$

(see Appendix B). In this notation, $S$ stands for "sensitivity index", the first symbol in the parentheses (here BFI) indicates the output that is assessed, and the second symbol (here a) the uncertain input. Sometimes this dimensionless index is also called "elasticity index".

The sensitivity index for the parameter $\mathrm{BFI}_{\max }$ is

$$
\begin{aligned}
S\left(\mathrm{BFI} \mid \mathrm{BFI}_{\max }\right) & =\frac{\Delta_{\mathrm{BFI}_{\max }} \mathrm{BFI}}{\mathrm{BFI}} / \frac{\Delta \mathrm{BFI}_{\max }}{\mathrm{BFI}_{\max }} \\
& =\frac{(a-1)(a \mathrm{BFI}-1)}{\left(1-a \mathrm{BFI}_{\max }\right)^{2}} \frac{\mathrm{BFI}_{\max }}{\mathrm{BFI}}
\end{aligned}
$$

(see Appendix B).

For specific values of $a, \mathrm{BFI}_{\max }$, and $\mathrm{BFI}$, the sensitivity indices $S(\mathrm{BFI} \mid a)$ and $S\left(\mathrm{BFI} \mid \mathrm{BFI}_{\max }\right)$ can now be calculated and compared.

\subsection{Initial value $b_{0}$}

The user of the filter algorithm has to choose an initial baseflow value $b_{0}$. In the present section, the sensitivity of the baseflow index to this value will be ascertained.

Equation (1) can be written as

$b_{k}=A b_{k-1}+B y_{k}$

with

$A=\frac{\left(1-\mathrm{BFI}_{\max }\right) a}{1-a \mathrm{BFI}_{\max }}$

and

$B=\frac{(1-a) \mathrm{BFI}_{\max }}{1-a \mathrm{BFI}_{\max }}$.

The baseflow $b_{k}$ at the time step $k$ is now traced back to the initial value $b_{0}$ :

$$
\begin{aligned}
b_{k} & =A b_{k-1}+B y_{k} \\
& =A\left(A b_{k-2}+B y_{k-1}\right)+B y_{k} \\
& =A^{2} b_{k-2}+A B y_{k-1}+B y_{k} \\
& =\ldots \\
& =A^{k} b_{0}+B \sum_{i=1}^{k} A^{i-1} y_{k-i+1} .
\end{aligned}
$$

Thus, the partial derivative of $b_{k}$ with respect to $b_{0}$ is

$$
\frac{\partial b_{k}}{\partial b_{0}}=A^{k} \text {. }
$$

The partial derivative of BFI with respect to $b_{0}$ is

$\frac{\partial \mathrm{BFI}}{\partial b_{0}}=\frac{\partial}{\partial b_{0}} \frac{b}{y}=\frac{1}{y} \sum_{k=1}^{n} \frac{\partial b_{k}}{\partial b_{0}}=\frac{1}{y} \sum_{k=1}^{n} A^{k}$.

For long time series (number $n$ of observations $\rightarrow \infty$ ):

$$
\frac{\partial \mathrm{BFI}}{\partial b_{0}} \approx \frac{1}{y} \lim _{n \rightarrow \infty} \sum_{k=1}^{n} A^{k}
$$

Because of $|A|<1$, the limit of the geometric series $\sum_{k=1}^{n} A^{k}$ for $n \rightarrow \infty$ is $\frac{A}{1-A}$ :

$\frac{\partial \mathrm{BFI}}{\partial b_{0}} \approx \frac{1}{y} \frac{A}{1-A}=\frac{1}{y} \frac{\left(1-\mathrm{BFI}_{\max }\right) a}{1-a}$.

The longer the time series, the greater is the sum $y$ of the measured streamflow values and the smaller is the right side of Eq. (22). In other words: for long time series the influence of the initial value $b_{0}$ on the baseflow index BFI becomes negligible.

\section{Application}

\subsection{Data and results}

An empirical sensitivity analysis requires several runs of the filter over the hydrograph of a specific stream, each one with different values of the two filter parameters. Subsequently, the resulting time series of baseflow have to be analysed to ascertain how the baseflow index varies. This finally allows the calculation of the sensitivity indices. Alternatively, only one filter run and calculation of the baseflow index is sufficient, if Eqs. (14) and (15) are used for assessing the sensitivity indices.

This method has been applied to the 65 catchments whose baseflow indices BFI were calculated by Eckhardt (2008). The results are summarised in Table 1. Two catchment types are distinguished: catchments with a perennial stream and porous aquifer, and catchments with an ephemeral stream and porous aquifer. Eckhardt (2005) suggested attributing a $\mathrm{BFI}_{\max }$ value of 0.80 to the former and of 0.50 to the latter. The recession constant $a$ of each catchment was determined by a recession analysis as described by Eckhardt (2008), the respective sensitivity indices were calculated with Eqs. (14) and (15).

\subsection{Discussion}

The analytical sensitivity analysis shows that the recession constant $a$ influences the calculated baseflow index BFI more than the filter parameter $\mathrm{BFI}_{\max }$. In the case of the catchments with perennial stream and porous aquifer, for example, the value $S(\mathrm{BFI} \mid a)=-0.77$ signifies that a relative error of 
Table 1. Results of the analysis of 65 North American catchments (mean values and their standard deviation).

\begin{tabular}{lrrrrrr}
\hline catchment type & number & $a$ & BFI $_{\max }$ & $\mathrm{BFI}$ & $S(\mathrm{BFI} \mid a)$ & $S\left(\mathrm{BFI} \mid \mathrm{BFI} I_{\max }\right)$ \\
\hline perennial stream, & 60 & 0.970 & 0.80 & 0.67 & -0.77 & 0.26 \\
porous aquifer & & \pm 0.001 & & \pm 0.01 & \pm 0.07 & \pm 0.01 \\
\hline ephemeral stream, & 5 & 0.961 & 0.50 & 0.42 & -0.42 & 0.11 \\
porous aquifer & & \pm 0.004 & & \pm 0.04 & \pm 0.22 & \pm 0.03 \\
\hline
\end{tabular}

$X$ percent in $a$ causes a relative error of -0.77 times $X$ percent in BFI. A relative error of $X$ percent in $\mathrm{BFI}_{\max }$ causes only a relative error of 0.26 times $X$ percent in $B F I$. This is good news because the recession constant $a$ can be determined by a recession analysis whereas an optimal $\mathrm{BFI}_{\max }$ value cannot be derived from the streamflow measurements alone. Therefore, the value of $\mathrm{BFI}_{\max }$ will be more uncertain than the value of $a$.

At first glance, the finding that the parameter $a$ has a stronger influence on the calculated baseflow index than the parameter $\mathrm{BFI}_{\max }$ seems to contradict the result of the empirical sensitivity analysis of Eckhardt (2005) which used hydrographs of two catchments not belonging to the pool of the 65 catchments analysed for the present paper.

- For a catchment with a perennial stream and porous aquifer, and assuming values of $a=0.925$ and $\mathrm{BFI}_{\max }=0.75$, the baseflow index was found to be $\mathrm{BFI}=0.72$ and sensitivity indices $S(\bar{b} \mid a)=-0.55$ and $S\left(\bar{b} \mid \mathrm{BFI}_{\max }\right)=0.96$ were calculated $(\bar{b}$ : mean value of the baseflow).

- For a catchment with a perennial stream and hard rock aquifer, and assuming values of $a=0.925$ and $\mathrm{BFI}_{\max }=0.25$, the baseflow index was found to be $\mathrm{BFI}=0.25$ and the sensitivity indices were $S(\bar{b} \mid a)=0.00$ and $S\left(\bar{b} \mid \mathrm{BFI}_{\max }\right)=0.98$.

Therefore, the conclusion was that $\mathrm{BFI}_{\max }$ is the more critical parameter.

Indeed, this is confirmed if we insert only the two afore-mentioned sets of values into Eqs. (14) and (15). With $a=0.925, \mathrm{BFI}_{\max }=0.75$, and $\mathrm{BFI}=0.72$ one gets $S(\mathrm{BFI} \mid a)=-0.10$ and $S\left(\mathrm{BFI} \mid \mathrm{BFI}_{\max }\right)=0.28$. With $a=0.925$ $\mathrm{BFI}_{\max }=0.25$, and $\mathrm{BFI}=0.25$ one gets $S(\mathrm{BFI} \mid a)=0.00$ and $S\left(\mathrm{BFI} \mid \mathrm{BFI}_{\max }\right)=0.10$. This, however, is obviously a nonrepresentative result. In the case of the first catchment, the main reason is that the value $a=0.925$ of the recession constant, which was arbitrarily choosen as a starting point for the empirical sensitivity analysis by Eckhardt (2005), is too small. If the recession analysis of Eckhardt (2008) is applied, it is found that the actual recession constant for this catchment is about 0.96. According to Eq. (14), however, the sensitivity index $S(\mathrm{BFI} \mid a)$ is the greater the greater $a$ is. With $a=0.925$ the sensitivity index $S(\mathrm{BFI} \mid a)$ was underrated. In the case of the second catchment, the finding $S(\mathrm{BFI} \mid a)=0.00$ is a consequence of the special situation that $\mathrm{BFI}_{\max }$ equals $\mathrm{BFI}$.

We have here a further argument for the analytical sensitivity analysis: because it requires less effort than an empirical sensitivity analysis once the Eqs. (14) and (15) are derived, more catchments can be included and hence a more reliable conclusion can be drawn.

\section{Conclusions}

The finding that $\mathrm{BFI}_{\max }$ is the less critical parameter in the filter Eq. (1) is favourable in that $\mathrm{BFI}_{\max }$ cannot be derived from the streamflow measurements and therefore is more uncertain than the other filter parameter, the recession constant $a$. Optimal $\mathrm{BFI}_{\max }$ values have to be found by calibration. Gonzales et al. (2009), for example, have calibrated the filter (Eq. 1) by means of a tracer-based separation using dissolved silica and found an optimal $\mathrm{BFI}_{\max }$ value of 0.92 for a Dutch catchment. Eckhardt (2005) suggested $\mathrm{BFI}_{\max }=0.80$ for such a catchment with a perennial stream and porous aquifer. Thus there may be an uncertainty of about 0.15 or $19 \%$ in the filter parameter $\mathrm{BFI}_{\max }$. The sensitivity index $S\left(\mathrm{BFI} \mid \mathrm{BFI}_{\max }\right)=0.26$ indicates that such an error leads to a mean error in the calculated baseflow index BFI of only $0.26 \times 19 \%=5 \%$. For catchments with ephemeral stream and porous aquifer, the uncertainty is smaller yet.

Of course, these values only characterise mean conditions derived for the 65 North American catchments presented by Eckhardt (2008). The baseflow index of a specific catchment can show another sensitivity to uncertainties in the filter parameters. However, this can easily be checked by means of Eqs. (14) and (15), which herewith provide important additional information to this baseflow separation technique. 


\section{Appendix A}

Calculation of the partial derivatives

$$
\begin{aligned}
\frac{\partial b_{k}}{\partial a}= & \frac{\partial}{\partial a} \frac{\left(1-\mathrm{BFI}_{\max }\right) a b_{k-1}+(1-a) \mathrm{BFI}_{\max } y_{k}}{1-a \mathrm{BFI}_{\max }} \\
= & \left(1-\mathrm{BFI}_{\max }\right) b_{k-1} \frac{\partial}{\partial a} \frac{a}{1-a \mathrm{BFI}_{\max }} \\
& +\mathrm{BFI}_{\max } y_{k} \frac{\partial}{\partial a} \frac{1-a}{1-a \mathrm{BFI}_{\max }} \\
= & \left(1-\mathrm{BFI}_{\max }\right) b_{k-1} \frac{1}{\left(1-a \mathrm{BFI}_{\max }\right)^{2}} \\
& +\mathrm{BFI}_{\max } y_{k} \frac{\mathrm{BFI}_{\max }-1}{\left(1-a \mathrm{BFI}_{\max }\right)^{2}} \\
= & \frac{\left(1-\mathrm{BFI}_{\max }\right)\left(b_{k-1}-\mathrm{BFI}_{\max } y_{k}\right)}{\left(1-a \mathrm{BFI}_{\max }\right)^{2}} \\
\frac{\partial b_{k}}{\partial \mathrm{BFI}_{\max }} & =a b_{k-1} \frac{\partial}{\partial \mathrm{BFI}_{\max } \frac{1-a \mathrm{BFI}_{\max }}{1-\mathrm{BFI}_{\max }}} \\
& +(1-a) y_{k} \frac{\partial}{\partial \mathrm{BFI}_{\max }} \frac{\mathrm{BFI}_{\max }}{1-a \mathrm{BFI}_{\max }} \\
& =a b_{k-1} \frac{a-1}{\left(1-a \mathrm{BFI}_{\max }\right)^{2}} \\
& +(1-a) y_{k} \frac{1}{\left(1-a \mathrm{BFI}_{\max }\right)^{2}} \\
& =\frac{(a-1)\left(a b_{k-1}-y_{k}\right)}{\left(1-a \mathrm{BFI}_{\max }\right)^{2}}
\end{aligned}
$$$$
\frac{\partial \mathrm{BFI}}{\partial a}=\frac{\partial}{\partial a} \frac{b}{y}=\frac{1}{y} \sum_{k=1}^{n} \frac{\partial b_{k}}{\partial a}
$$$$
=\frac{1}{y} \sum_{k=1}^{n} \frac{\left(1-\mathrm{BFI}_{\max }\right)\left(b_{k-1}-\mathrm{BFI}_{\max } y_{k}\right)}{\left(1-a \mathrm{BFI}_{\max }\right)^{2}} \text { (see Eq. A1) }
$$$$
=\frac{1}{y} \frac{1-\mathrm{BFI}_{\max }}{\left(1-a \mathrm{BFI}_{\max }\right)^{2}} \sum_{k=1}^{n}\left(b_{k-1}-\mathrm{BFI}_{\max } y_{k}\right)
$$$$
=\frac{1}{y} \frac{1-\mathrm{BFI}_{\max }}{\left(1-a \mathrm{BFI}_{\max }\right)^{2}}\left(b+b_{0}-b_{n}-\mathrm{BFI}_{\max } y\right)
$$$$
\frac{\partial \mathrm{BFI}}{\partial \mathrm{BFI}_{\max }}=\frac{1}{y} \sum_{k=1}^{n} \frac{\partial b_{k}}{\partial \mathrm{BFI}_{\max }}
$$$$
=\frac{1}{y} \sum_{k=1}^{n} \frac{(a-1)\left(a b_{k-1}-y_{k}\right)}{\left(1-a \mathrm{BFI}_{\max }\right)^{2}}(\text { see Eq. A2) }
$$$$
=\frac{1}{y} \frac{a-1}{\left(1-a \mathrm{BFI}_{\max }\right)^{2}} \sum_{k=1}^{n}\left(a b_{k-1}-y_{k}\right)
$$$$
=\frac{1}{y} \frac{a-1}{\left(1-a \mathrm{BFI}_{\max }\right)^{2}}\left[a\left(b+b_{0}-b_{n}\right)-y\right] \text {. }
$$

\section{Appendix B}

Calculation of the sensitivity indices

$$
\begin{aligned}
S(\mathrm{BFI} \mid a) & =\frac{\Delta_{\mathrm{a}} \mathrm{BFI}}{\mathrm{BFI}} / \frac{\Delta a}{a} \\
& =\frac{\left(1-\mathrm{BFI}_{\max }\right)\left(b-\mathrm{BFI}_{\max } y\right)}{y\left(1-a \mathrm{BFI}_{\max }\right)^{2}} \Delta a \frac{a}{\mathrm{BFI} \Delta a}
\end{aligned}
$$

(see Eq. 12). With $b=$ BFI $y$ (Eq. 7) one can also write

$$
\begin{aligned}
S(\mathrm{BFI} \mid a)= & \frac{\left(1-\mathrm{BFI}_{\max }\right)\left(\mathrm{BFI} y-\mathrm{BFI}_{\max } y\right)}{y\left(1-a \mathrm{BFI}_{\max }\right)^{2}} \frac{a}{\mathrm{BFI}} \\
= & \frac{\left(1-\mathrm{BFI}_{\max }\right)\left(\mathrm{BFI}-\mathrm{BFI}_{\max }\right)}{\left(1-a \mathrm{BFI}_{\max }\right)^{2}} \frac{a}{\mathrm{BFI}} \\
S\left(\mathrm{BFI}^{2} \mathrm{BFI}_{\max }\right) & =\frac{\Delta \mathrm{BFI}_{\max } \mathrm{BFI}}{\mathrm{BFI}} / \frac{\Delta \mathrm{BFI}_{\max }}{\mathrm{BFI}_{\max }} \\
& =\frac{(a-1)(a b-y)}{y\left(1-a \mathrm{BFI}_{\max }\right)^{2}} \Delta \mathrm{BFI}_{\max } \\
& \frac{\mathrm{BFI}_{\max }}{\mathrm{BFI} \Delta \mathrm{BFI}_{\max }}(\mathrm{see} \mathrm{Eq} .13) \\
= & \frac{(a-1)\left(a \mathrm{BFI}_{-1}-1\right)}{\left(1-a \mathrm{BFI}_{\max }\right)^{2}} \frac{\mathrm{BFI}_{\max }}{\mathrm{BFI}} .
\end{aligned}
$$

Edited by: N. Verhoest

\section{References}

Boughton, W. C.: A hydrograph-based model for estimating the water yield of ungauged catchments. Hydrology and Water Resources Symposium, Institution of Engineers Australia, Newcastle, 317-324, 1993.

Chapman, T. G. and Maxwell, A. I.: Baseflow separation - Comparison of numerical methods with tracer experiments, Hydrological and Water Resources Symposium, Institution of Engineers Australia, Hobart, 539-545, 1996.

Eckhardt, K.: How to construct recursive digital filters for baseflow separation, Hydrol. Process., 19, 507-515, 2005.

Eckhardt, K.: A comparison of baseflow indices, which were calculated with seven different baseflow separation methods, J. Hydrol., 352, 168-173, 2008.

Furey, P. and Gupta, V. K.: A physically based filter for separating base flow from streamflow time series, Water Resour. Res., 37, 2709-2722, 2001.

Gonzales, A. L., Nonner, J., Heijkers, J., and Uhlenbrook, S.: Comparison of different base flow separation methods in a lowland catchment, Hydrol. Earth Syst. Sci., 13, 2055-2068, doi:10.5194/hess-13-2055-2009, 2009.

Huyck, A. A. O., Pauwels, V. R. N., and Verhoest, N. E. C.: A base flow separation algorithm based on the linearized Boussinesq equation for complex hillslopes, Water Resour. Res., 41, W08415, doi:10.1029/2004WR003789, 2005. 